\title{
Infection during the first year in patients treated with CD19 CAR T cells for diffuse large B cell lymphoma
}

Kitsada Wudhikarn (1) ${ }^{1,2}$, M. Lia Palomba (10 3,4, Martina Pennisi 1,5, Marta Garcia-Recio ${ }^{1}$, Jessica R. Flynn 6 , Sean M. Devlin', Aishat Afuye (1)', Mari Lynne Silverberg ${ }^{1}$, Molly A. Maloy ${ }^{1}$, Gunjan L. Shah ${ }^{1,4}$, Michael Scordo ${ }^{1,4}$, Parastoo B. Dahi $\mathbb{B}^{1,4}$, Craig S. Sauter ${ }^{1,4}$, Connie L. Batlevi $\mathbb{1}^{3,4}$, Bianca D. Santomasso ${ }^{4,7}$, Elena Mead ${ }^{4,8}$, Susan K. Seo ${ }^{4,9}$ and Miguel-Angel Perales (1,4

\begin{abstract}
CD19-targeted chimeric antigen receptor (CAR) T cell therapy is an effective treatment for diffuse large B cell lymphoma (DLBCL). In addition to cytokine release syndrome (CRS) and immune effector cell-associated neurotoxicity (ICANS), B cell aplasia and hypogammaglobulinemia are common toxicities predisposing these patients to infections. We analyzed 60 patients with DLBCL treated with FDA-approved CD19 CAR T cells and report the incidence, risk factors, and management of infections during the first year after treatment. A total of 101 infectious events were observed, including 25 mild, 51 moderate, 23 severe, 1 life-threatening, and 1 fatal infection. Bacteria were the most common causative pathogens. The cumulative incidence of overall, bacterial, severe bacterial, viral, and fungal infection at 1 year were $63.3 \%, 57.2 \%, 29.6 \%, 44.7 \%$, and 4\%, respectively. In multivariate analyses, the use of systemic corticosteroids for the management of CRS or ICANS was associated with an increased risk of infections and prolonged admission. Impaired performance status and history of infections within 30 days before CAR T cell therapy was a risk factor for severe bacterial infection. In conclusion, infections were common within the first 60 days after CAR T cell therapy, however, they were not associated with an increased risk of death.
\end{abstract}

\section{Introduction}

CD19-directed chimeric antigen receptor (CAR) T cell is a major breakthrough that has revolutionized the treatment paradigm of relapsed/refractory (RR) diffuse large B cell lymphoma (DLBCL) over the past recent years $^{1,2}$. Despite the significant anti-lymphoma activity, CD19 CAR T cells possess unique toxicities. Besides immune-mediated toxicities, B cell aplasia, and resultant hypogammaglobulinemia are common consequences of

Correspondence: Miguel-Angel Perales (peralesm@mskcc.org)

${ }^{1}$ Adult Bone Marrow Transplant Service, Department of Medicine, Memorial Sloan Kettering Cancer Center, New York, NY, USA

${ }^{2}$ Division of Hematology and Research Unit in Translational Hematology, Department of Medicine, Chulalongkorn University, Bangkok, Thailand

Full list of author information is available at the end of the article

These authors contributed equally: Kitsada Wudhikarn, M. Lia Palomba

These authors jointly supervised this work: Susan K. Seo, Miguel-Angel Perales.
CD19 CAR T cell therapy, which put patients at risk for infectious complications ${ }^{3,4}$. Although there have been some initial reports on the infectious complications of CAR $T$ cell therapy, most studies included patients treated in clinical trials or with multiple underlying B cell malignancies ${ }^{5-10}$. Currently, there are limited real-world data on infectious risks in patients treated with CD19 CAR T cell therapy for DLBCL. Moreover, little is known about proper prophylaxis and management strategies for these patients. Herein, we describe the pattern, incidence, impact of infections, including infection prophylactic strategies, in patients with DLBCL who received FDAapproved CAR T cell therapy at Memorial Sloan Kettering Cancer Center (MSKCC). 
Table 1 Infection prophylaxis guideline for chimeric antigen receptor T cell patients at Memorial Sloan Kettering Cancer Center.

\begin{tabular}{|c|c|c|}
\hline & Recommended agent & Duration \\
\hline Antiviral prophylaxis & Acyclovir ${ }^{a} 400$ mg orally twice daily & $\begin{array}{l}\text { Commence with chemotherapy and continue for at } \\
\text { least } 6 \text { months post-CAR T infusion }\end{array}$ \\
\hline Anti-Pneumocystis prophylaxis ${ }^{b}$ & $\begin{array}{l}\text { Trimethoprim/Sulfamethoxazole } 1 \text { double-strengh } \\
\text { tablet orally three times a week } \\
\text { OR, if allergic or intolerant, } \\
\text { Aerosolized pentamidine } 300 \text { mg monthly }\end{array}$ & $\begin{array}{l}\text { Commence with chemotherapy and continue for } \\
3 \text { months post-CAR T infusion } \\
\text { Consider extending duration beyond } 3 \text { months with } \\
\text { persistent lymphopenia (CD } 4<200 \text { cells } / \mu \mathrm{L} \text { ) }\end{array}$ \\
\hline Antifungal prophylaxis & Fluconazole $^{a} 200$ mg orally daily & $\begin{array}{l}\text { Commence with chemotherapy and continue until } \\
\text { neutrophil recovery (ANC }>500 \text { cells/ } \mu \mathrm{L} \text { for at least } \\
3 \text { days) }\end{array}$ \\
\hline $\begin{array}{l}\text { Antifungal prophylaxis for patients at } \\
\text { high risk for mold infection } \\
\text { (e.g., prednisone }>20 \mathrm{mg} \text { for } \\
>2 \text { weeks or equivalent) }\end{array}$ & Voriconazole $^{\mathrm{a}, \mathrm{c}} 200 \mathrm{mg}$ orally twice daily & \\
\hline
\end{tabular}

CAR chimeric antigen receptor, ANC absolute neutrophil count.

${ }^{\text {a }}$ Prophylaxis was converted to an intravenous formulation if patient was unable to tolerate oral intake.

${ }^{b}$ For patients unable to take sulfa or pentamidine, dapsone $100 \mathrm{mg}$ daily or atovaquone $1500 \mathrm{mg}$ daily were alternatives.

'Voriconazole was switched to micafungin $100 \mathrm{mg}$ daily $48 \mathrm{~h}$ prior to and restarted $48 \mathrm{~h}$ after cyclophosphamide conditioning.

\section{Sample and methods}

The study cohort included 60 consecutive patients with RR DLBCL who received FDA-approved CAR $T$ cell therapy (axicabtagene ciloleucel-Yescarta; Kite Pharma, Santa Monica, CA or tisagenlecleucel-Kymriah; Novartis, Basel, Switzerland) at MSKCC between January 2018 and June 2019. Baseline clinical characteristics, patterns of antimicrobial prophylaxis, treatment of infection, and laboratory data, including blood count, CD4 lymphocyte, and immunoglobulin (Ig) level before lymphodepletion (LD) chemotherapy were abstracted from the electronic health records (EHR). Systemic bridging therapy were classified to intensive or non-intensive regimens. Intensive regimens included multi-agent immunochemotherapy e.g. CHOP-like, bendamustine-based, gemcitabinebased, high dose cytarabine-based, and ICE regimens. Non-intensive regimens included single-agent rituximab, immunomodulatory agent or small molecule inhibitor. The LD chemotherapy before CAR $\mathrm{T}$ cell infusion was selected based on recommended regimens in the package insert of each approved CAR $\mathrm{T}$ product. In patients who received axicabtagene ciloleucel, LD chemotherapy consisted of fludarabine $30 \mathrm{mg} / \mathrm{m}^{2}$, and cyclophosphamide $500 \mathrm{mg} / \mathrm{m}^{2}$ daily for 3 days. For patients receiving tisagenlecleucel, fludarabine $25 \mathrm{mg} / \mathrm{m}^{2}$ and cyclophosphamide $250 \mathrm{mg} / \mathrm{m}^{2}$ daily for 3 days or bendamustine $90 \mathrm{mg} / \mathrm{m}^{2}$ daily for 2 days was given for LD.

Prior to March 2019, there was no formal institutional guideline for antimicrobial prophylaxis or infection surveillance in patients treated with CAR T cell therapy, and treatment regimen was based on the autologous stem cell transplant (SCT) protocol or left to the primary physician's preference. Standardized guidelines for CAR T cell patients were implemented in March 2019 and included acyclovir for herpes simplex virus (HSV) prophylaxis, fluconazole for antifungal prophylaxis, and trimethoprim/ sulfamethoxazole or aerosolized pentamidine for Pneumocystis jiroveci prophylaxis (Table 1).

All infections were documented from the day of CAR T cell infusion through 1-year post-CAR $\mathrm{T}$ cell therapy, last follow-up, or relapse/progression, whichever came first. Infection events included both confirmed infections in which causative pathogens were identified, and probable infections diagnosed by the presence of fever plus localized physical exam and/or radiological findings. Any episode of culture-negative neutropenic fever in the absence of localized infection within the first 30 days after CAR $T$ cell infusion was excluded from the analysis owing to the high probability of overlap with cytokine release syndromes (CRS). We classified types of infection according to causal pathogens, including bacterial, viral, fungal, and protozoal infection. Bacterial infections were further classified into organ-specific infection or bacteremia without localizing organ involvement. Infection severity was graded as mild, moderate, severe, lifethreatening, or fatal, according to published criteria ${ }^{5,11}$. Mild infection was defined as not requiring antimicrobial therapy. Moderate infection entailed therapy with an oral antimicrobial medication. Severe infection was defined as infection requiring receipt of intravenous antimicrobial treatment. Life-threatening infection was defined as the presence of end-organ or cardiovascular compromise. 
Cumulative incidence of any infection, bacterial infection, severe bacterial infection, and viral infection were reported and separated by time after CAR $\mathrm{T}$ cell infusion (0-30 days, 31-100 days, 101-180 days, and 181-365 days). The data cutoff for statistical analysis was December 31, 2019.

\section{Statistical analysis}

We reported continuous variables using median and range. Categorical data were presented as a percentage. Overall survival was analyzed by Kaplan-Meier methodology and infections were treated as time-dependent covariates. Cumulative incidence of time to the first infection was evaluated with progression of disease, relapse, and death from non-infection causes as competing events. Factors associated with infection were identified by univariate analysis using cause-specific hazard ratios and 95\% confidence intervals. CRS, immune effector cell-associated neurotoxicity syndrome (ICANS), corticosteroid, tocilizumab, and intravenous immunoglobulin (IVIG) were treated as time-dependent covariates. $P$-values less than 0.10 were considered for multivariate analysis using cause-specific hazard ratios. All statistical analyses were performed by $R$ program version 3.6.0. The cmprsk package was used for the cumulative incidence of infection. The institutional review board and the ethic committee of MSKCC granted approval for conducting the study.

\section{Results}

\section{Baseline clinical characteristics}

Table 2 summarizes the baseline clinical characteristics of the 60 patients in this cohort. The median age at the time of CAR T treatment was 63 years (19.5-85.9 years). Thirty-five patients (58\%) had de novo DLBCL. Patients had a median of $4^{2-9}$ prior lines of treatment before CAR $\mathrm{T}$ cells, and $16(26.7 \%)$ underwent prior hematopoietic cell transplantation. Thirty-eight patients (63.3\%) received bridging therapy before CAR T cells (4 radiation therapy, 33 immunochemotherapy and 1 combined modality). Forty-three patients $(71.7 \%)$ were treated with axicabtagene ciloleucel, and 17 (28.3\%) received tisagenlecleucel. The median length of hospital stay for CAR $\mathrm{T}$ cell admission was 17 days (0-72 days). Thirteen patients (21.7\%) received CAR T cell therapy after the institutional antimicrobial prophylactic protocol was implemented.

\section{Baseline infection and antimicrobial prophylaxis}

Nineteen patients (31.7\%) received systemic antibacterial treatment for an infection within 30 days before the CAR $\mathrm{T}$ cell infusion. Three of these patients continued antibiotics through the admission of CAR $\mathrm{T}$ cell therapy. Thirty-one patients (51.7\%) received antibacterial prophylaxis (Supplementary Table S1). All patients
Table 2 Baseline characteristics of large B cell lymphoma treated with CD19 chimeric antigen receptor $T$ cells.

\begin{tabular}{|c|c|}
\hline Baseline parameters & $N=60(\%)$ \\
\hline $\begin{array}{l}\text { Median Age at Chimeric Antigen Receptor T Cell } \\
\text { (range) }\end{array}$ & $63(19.5-85.9)$ years \\
\hline Gender (Male:Female) & $42: 18$ \\
\hline \multicolumn{2}{|l|}{ Histopathological diagnosis } \\
\hline De novo diffuse large B cell lymphoma & $35(58.3)$ \\
\hline Transformed indolent lymphoma & $25(41.7)$ \\
\hline \multicolumn{2}{|l|}{ Stage } \\
\hline Stage $1-2$ & $14(23.3)$ \\
\hline Stage $3-4$ & $38(63.3)$ \\
\hline Not available & $8(13.3)$ \\
\hline \multicolumn{2}{|l|}{ ECOG Performance status } \\
\hline $0-1$ & $44(73.3)$ \\
\hline 2 & $10(16.7)$ \\
\hline 3 & $2(3.3)$ \\
\hline Not available & $4(6.7)$ \\
\hline $\begin{array}{l}\text { Median number of treatment lines prior to CAR T } \\
\text { cells (range) }\end{array}$ & $3(2-9)$ \\
\hline \multicolumn{2}{|l|}{ Response to prior treatments } \\
\hline Primary refractory disease & $10(16.7)$ \\
\hline Relapsed disease & $50(83.3)$ \\
\hline \multicolumn{2}{|l|}{ Presence of bulky disease } \\
\hline Yes & $9(15.0)$ \\
\hline No & $45(75.0)$ \\
\hline Not available & $6(10.0)$ \\
\hline \multicolumn{2}{|c|}{ History of hematopoietic stem cell transplant prior to CAR T cells } \\
\hline Allogeneic hematopoietic stem cell transplant ${ }^{a}$ & $12(20.0)$ \\
\hline $\begin{array}{l}\text { Autologous hematopoietic stem cell } \\
\text { transplant }^{\mathrm{a}}\end{array}$ & $5(8.3)$ \\
\hline No & $44(73.3)$ \\
\hline \multicolumn{2}{|l|}{ Bridging treatment before CAR T cell } \\
\hline High-Intensity systemic therapy & $23(38.3)$ \\
\hline Low-Intensity systemic therapy ${ }^{b}$ & $11(18.3)$ \\
\hline Radiotherapy ${ }^{\mathrm{b}}$ & $5(8.3)$ \\
\hline No bridging therapy or systemic corticosteroid & $22(36.7)$ \\
\hline $\begin{array}{l}\text { History of Infection within } 30 \text { days before CAR T } \\
\text { cell }\end{array}$ & $24(40.0)$ \\
\hline \multicolumn{2}{|l|}{ Lymphodepletion chemotherapy } \\
\hline Fludarabine cyclophosphamide & $57(95.0)$ \\
\hline Bendamustine & $3(95.0)$ \\
\hline \multicolumn{2}{|l|}{ CAR T cell product } \\
\hline Axicabtagene ciloleucel & $43(71.7)$ \\
\hline Tisagenlecleucel & $17(28.3)$ \\
\hline
\end{tabular}

ECOG Eastern Cooperative Oncology Group, CAR chimeric antigen receptor.

${ }^{a}$ One patient had both autologous and allogeneic hematopoietic stem cell transplant. ${ }^{b}$ One patient received combined non-intensive systemic and radiation therapy.

received antiviral prophylaxis for HSV, and 6 received entecavir due to the positive hepatitis B core antibody. Fifty-five patients $(91.7 \%)$ were given prophylaxis for Pneumocytis jiroveci. Forty-eight patients $(80 \%)$ received antifungal prophylaxis, 26 were initiated before CAR T cell infusion whereas the other 22 had antifungal prophylaxis started once absolute neutrophil count (ANC) was less than $500 \mu / \mathrm{mL}$ (median time from CAR T infusion to antifungal prophylaxis initiation of 7 days). 
Recovery of leukocytes and immunoglobulin levels (Table 3)

Baseline median ANC and absolute lymphocyte counts (ALC) before LD chemotherapy were 3850 $(200-10,600)$ and $600(100-2700)$ cells $/ \mu \mathrm{L}$, respectively. Two patients had grade 4 neutropenia (ANC $<500$ cells/ $\mu \mathrm{L})$ before LD therapy, as defined by CTCAE version $5.0^{12}$. Forty-seven of the remaining 58 patients $(81.0 \%)$ developed neutropenia grade 4 after LD therapy. The median duration of neutropenia grade 4 was 12 days (3-66 days). Ten patients had grade 4 neutropenia after day 30 ( 5 of which had persistent grade 4 neutropenia from the first 30 days). Thirty patients required at least one dose of growth factor support after CAR T cell therapy. Grade 3-5 lymphopenia beyond day 30 after CAR T cell was observed in 35 patients (58.3\%). Of 19 patients who had lymphocyte subset analysis at day 30 , all had B cell aplasia and the median $\mathrm{CD} 4^{+}$lymphocyte count was 116 cells $/ \mu \mathrm{L}(41-630$ cells $/ \mu \mathrm{L})$. Supplementary Table S2 summarizes the status of leukocyte subset reconstitution after CAR $\mathrm{T}$ cell infusion.

In 59 patients with available baseline IgG level before LD chemotherapy, the median IgG level was $487 \mathrm{mg} / \mathrm{dL}$ $(163-1399 \mathrm{mg} / \mathrm{dL})$, and 15 patients $(25 \%)$ had baseline hypogammaglobulinemia (IgG $\leq 400 \mathrm{mg} / \mathrm{dL}$ ). Immunoglobulin levels were checked at day 30 after CAR T cell therapy in 32 patients; 14 (43.8\%) had hypogammaglobulinemia. An additional 12 patients (37.5\%) developed hypogammaglobulinemia at later follow-up timepoints. Nineteen patients $(31.7 \%)$ received at least 1 dose of IVIG replacement, including $10(52.6 \%)$ who had IVIG after history of recurrent infections. Figure 1 illustrates patterns of leukocyte and IgG level during the CD19 CAR T cell treatment course.

\section{CRS and ICANS}

CRS was observed in 48 patients (80\%) (grade $\geq 3$ in 7 patients; $11.7 \%$ ) at a median onset of 2 days after CAR T cell infusion (0-11 days). ICANS was observed in 24 patients $(40 \%)$ and was grade $\geq 3$ in 13 patients. The median onset of ICANS was 5 days after infusion. Of patients who developed CRS or ICANS, 25 (53.2\%) received systemic corticosteroid with a median duration of 4 days (1-58 days). The median prednisone equivalent dose intensity of corticosteroid was $1.12 \mathrm{mg} / \mathrm{kg} / \mathrm{day}$ $(0.33-4.23 \mathrm{mg} / \mathrm{kg} /$ day) with the corresponding median cumulative dose of $380 \mathrm{mg}(66.7-4586 \mathrm{mg})$ or $8.1 \mathrm{mg} / \mathrm{kg}$ $(0.33-69.6 \mathrm{mg} / \mathrm{kg})$ prednisone equivalent. Patients who received systemic corticosteroid had longer median hospital stay than patients who did not (27 days vs. 14 days, $P<0.001)$.

Baseline c-reactive protein, procalcitonin, and IL-6 before CAR $\mathrm{T}$ cell infusion were elevated in $52(86.7 \%)$, 4 (7.4\%), and $38(63.3 \%)$ patients, respectively. The median peak procalcitonin level was $0.46(0.05-27.65) \mu \mathrm{g} / \mathrm{L}$.
Table 3 Baseline cytokine and immune function of large B cell lymphoma treated with CD19 chimeric antigen receptor $\mathbf{T}$ cells.

$N(\%)$

Baseline absolute neutrophil count prior to lymphodepletion

chemotherapy

Less than 500 cells/ $\mu \mathrm{L}$

$1(1.7)$

500-1000 cells/ $\mu \mathrm{L}$

$1(1.7)$

1000 cells/ML or higher

$58(96.7)$

Baseline absolute lymphocyte count prior to lymphodepletion chemotherapy

Less than 500 cells/ $\mu \mathrm{L}$

$20(33.3)$

500-1000 cells/ $\mu \mathrm{L}$

$29(48.3)$

1000 cells/ML or higher

$11(18.3)$

Baseline $\mathrm{CD}^{+}$lymphocyte count prior to lymphodepletion

chemotherapy (in 19 patients)

Less than 200 cells/ $\mathrm{\mu L}$

$8(42.1)$

200-500 cells/uL

$10(52.6)$

500 cells/ $\mathrm{LL}$ or higher

$1(5.3)$

Baseline immunoglobulin $\mathrm{G}$ level prior to lymphodepletion chemotherapy

Less than $400 \mathrm{mg} / \mathrm{dL} \quad 15$ (25.0)

$400 \mathrm{mg} / \mathrm{dL}$ or higher $\quad 45$ (75.0)

Baseline lactate dehydrogenase level prior to lymphodepletion

chemotherapy

Normal

$30(50.0)$

Elevate $x 1$ to $x 3$ upper normal limit

$24(40.0)$

Higher than $\times 3$ upper normal limit

$6(10.0)$

Median baseline interleukin-6 level prior to CAR T cell

$11.8(2.5-246.0)$ infusion (range, $\mathrm{pg} / \mathrm{mL}$ )

Median baseline ferritin level prior to CAR T cell

$302(8-8201)$

infusion (range, $\mathrm{ng} / \mathrm{mL}$ )

Median baseline C-reactive protein level prior to CAR T

$1.6(0.1-27.5)$

cell infusion (range, mg/L)

Median baseline procalcitonin level prior to CAR T cell

$0.1(0-3.5)$ infusion $(\mathrm{ng} / \mathrm{mL}$ )

CAR chimeric antigen receptor.

The trends of procalcitonin and IL-6 are shown in Supplementary Figs. S1 and S2, respectively.

\section{Incidence, characteristics, and patterns of infection after CAR T cell therapy}

Fifty-two of 60 patients (86.7\%) developed neutropenic fever within the first 30 days after CAR $\mathrm{T}$ cell infusion. With the median follow-up of 6 months (0.8-12 months), after excluding neutropenic fever without identified pathogen or localizing organ, there 


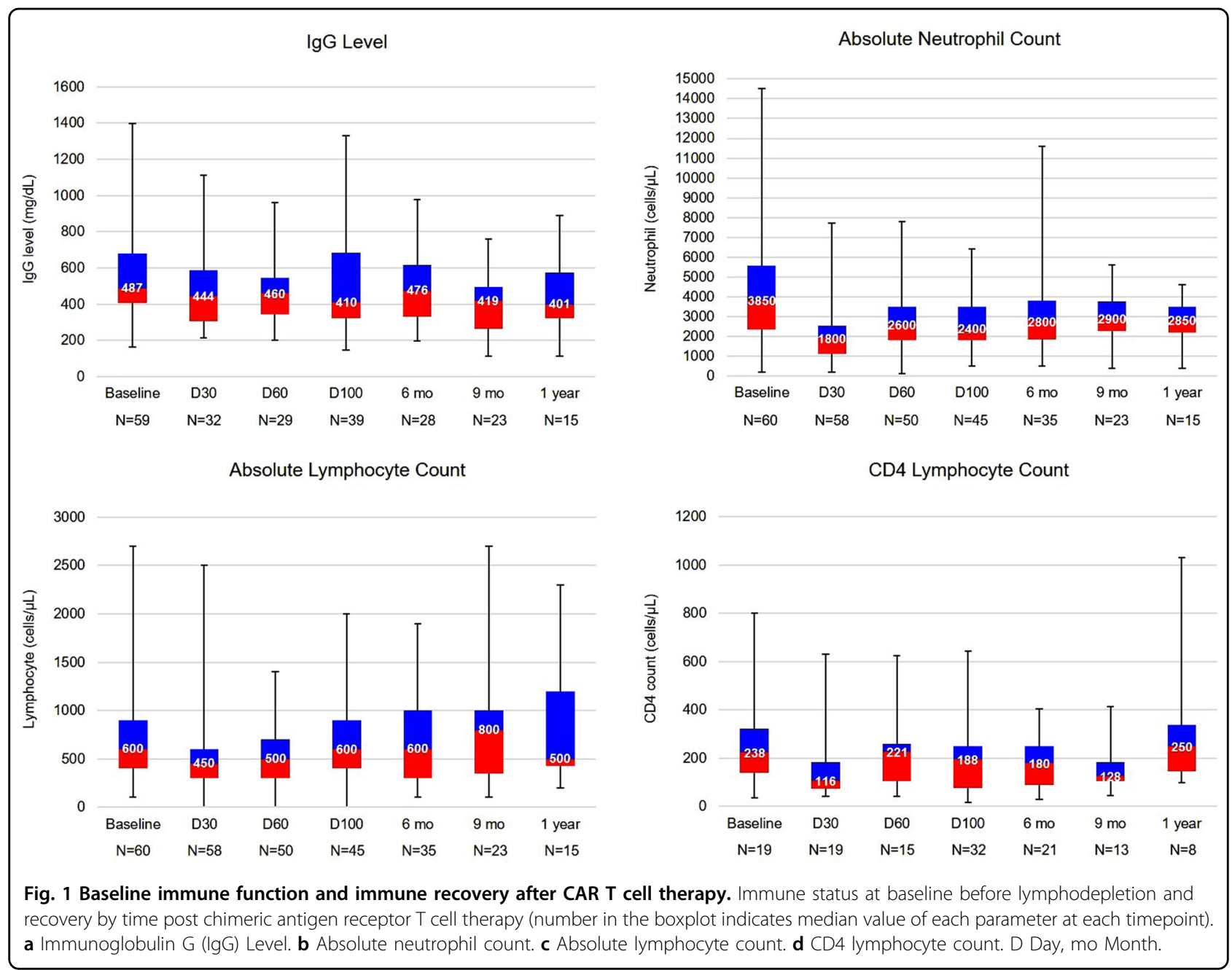

was a total of 101 infection events (60 bacterial, 38 viral, 2 fungal, and 1 protozoal) in 40 patients during the entire study period. Pathogenic organism were identified in 73 infection events (72\%) (60\% of bacterial, $92.1 \%$ of viral, $50 \%$ of fungal, and $100 \%$ of protozoal infection). Thirty-seven infection episodes (34.6\%) occurred within the first 30 days after CAR T cell therapy. Of 101 events, $23(22.8) \%$ infections were classified as severe, 1 (1.0\%) as life-threatening (Escherichia coli biliary sepsis), and 1 (1.0\%) fatal (influenza A pneumonia). Of all 101 infection events, 32 occurred during the initial CAR T cell admission. Among the other 69 infection episodes (bacterial; $n=42$, viral; $n=26$, fungal; $n=1$ ), which occurred following hospital discharge from CAR T cell therapy, 21 (bacterial; $n=14$, viral; $n=6$, fungal; $n=1$ ) required hospital readmission with the median hospital stay of 5 (2-37) days.

Figure 2 shows the distribution of bacterial or viral infection at each period post-CAR $\mathrm{T}$ cell infusion. The distribution of organ involvement and causative organism of bacterial infection are shown in Fig. 3 and
Supplementary Table S3. The 1-year cumulative incidence of all infections, bacterial, viral, and fungal infections were 63.3, 57.2, 44.7\%, and 4.0\%, respectively (Fig. 4, Table 4).

\section{Infection within the first 30 days of CAR T cell infusion}

Of 37 infection episodes that occurred within the first 30 days after CAR T cell infusion (Supplementary Tables S3-S6), bacterial infections were the most frequent with 25 events ( 15 moderate, 10 severe) in 20 patients. The median onset of the first bacterial infection was day 12 (0-30). A total of 15 events were organ-specific infections, whereas 10 were primary bacteremias. Organisms were identified in 19 definite infectious episodes with Clostridium difficile (colitis) being the most common causative bacterial pathogen $(n=7)$. The other 6 events were probable infections (including 3 lobar pneumonia, $3 \mathrm{soft}$ tissue infection). Piperacillin/tazobactam was the most common empirical anti-bacterial agent for neutropenic fever during the first 30 days in 38 patients (63.3\%), followed by cefepime in 7 patients. 
Ten viral infections occurred during the first 30 days $(8$ mild, 2 moderate) with the median onset at day 8 (0-26 days). Viral pathogens included respiratory

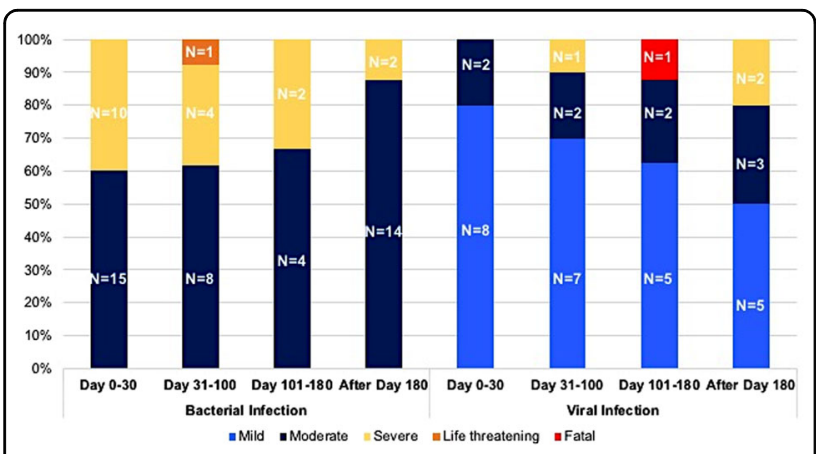

Fig. 2 Infections after CD19 CAR T cell therapy. Distribution of bacterial and viral infection by time post chimeric antigen receptor $T$ cell and severity. syncytial virus $(n=5)$, cytomegalovirus $(n=2)$, polyoma BK virus $(n=2)$, and norovirus $(n=1)$. Both cytomegalovirus infection were viremia without end organ involvement. There was 1 probable invasive aspergillosis pulmonary infection (elevated serum galactomannan antigen and consistent radiographic imaging), and 1 protozoal infection (Cryptosporidium parvum).

\section{Infection after day 30 post CAR T cell infusion}

Thirty-five bacterial infections were observed in 16 patients after day 30, including 12 events during day 31-100, 7 during day $101-180$, and 16 beyond day 180 (Supplementary Tables S3-S6). Six of these 16 patients had previous bacterial infection within the first 30 days. Among 35 bacterial infections, there were 26 moderate, 8 severe, and 1 fatal infection. Ninety-seven percent were organ-specific infections with urinary tract infection being the most common presentation $(n=11)$. Of 28 viral infections, 10 occurred during day $31-100,8$ occurred during day 101-180, and

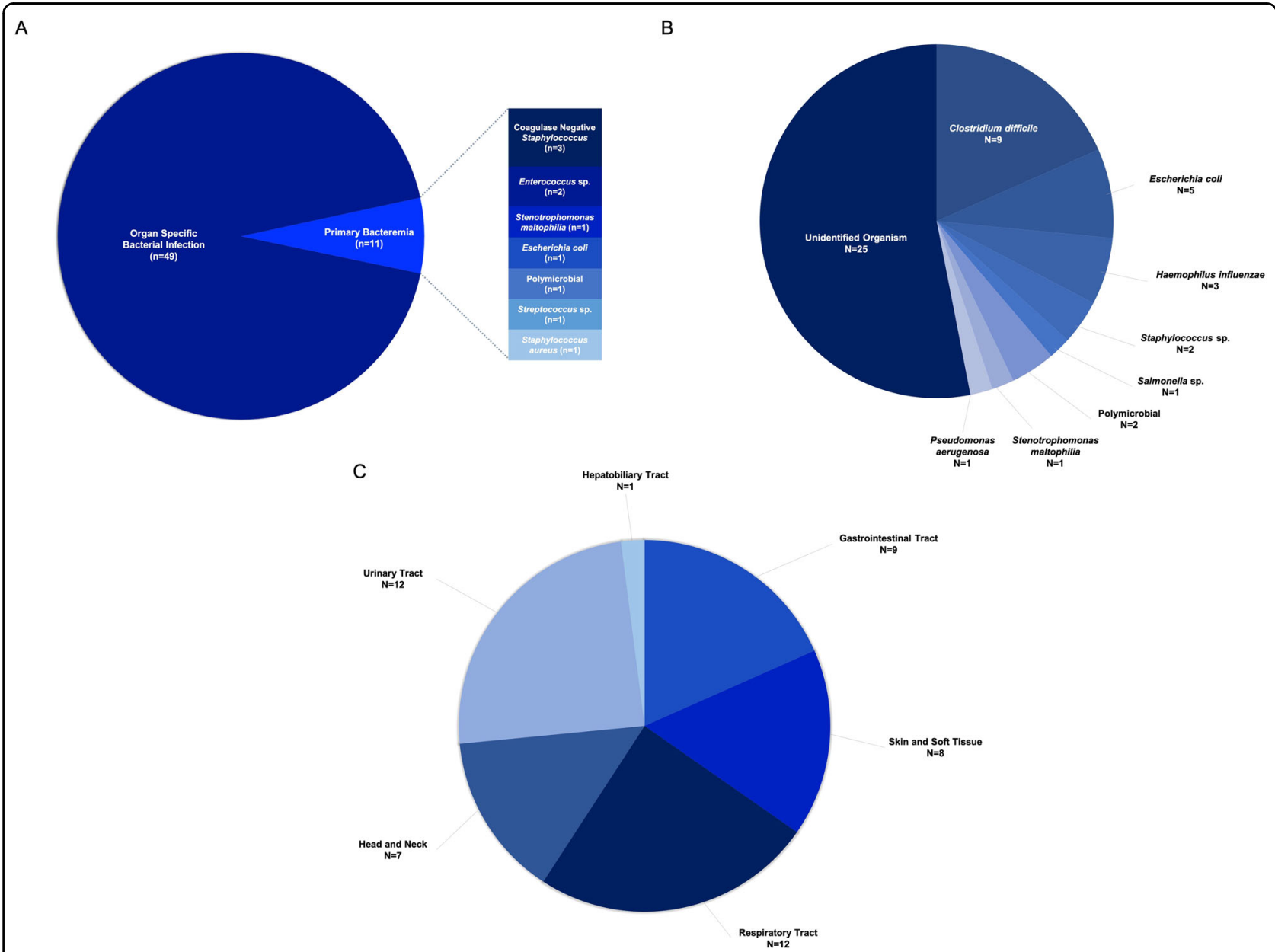

Fig. 3 Distribution of bacterial infection. a By localization - primary bacteremia vs. Localized infection. $\mathbf{b}$ Identified organism in localized bacterial infection. c Localized bacterial infection by involved organs. 

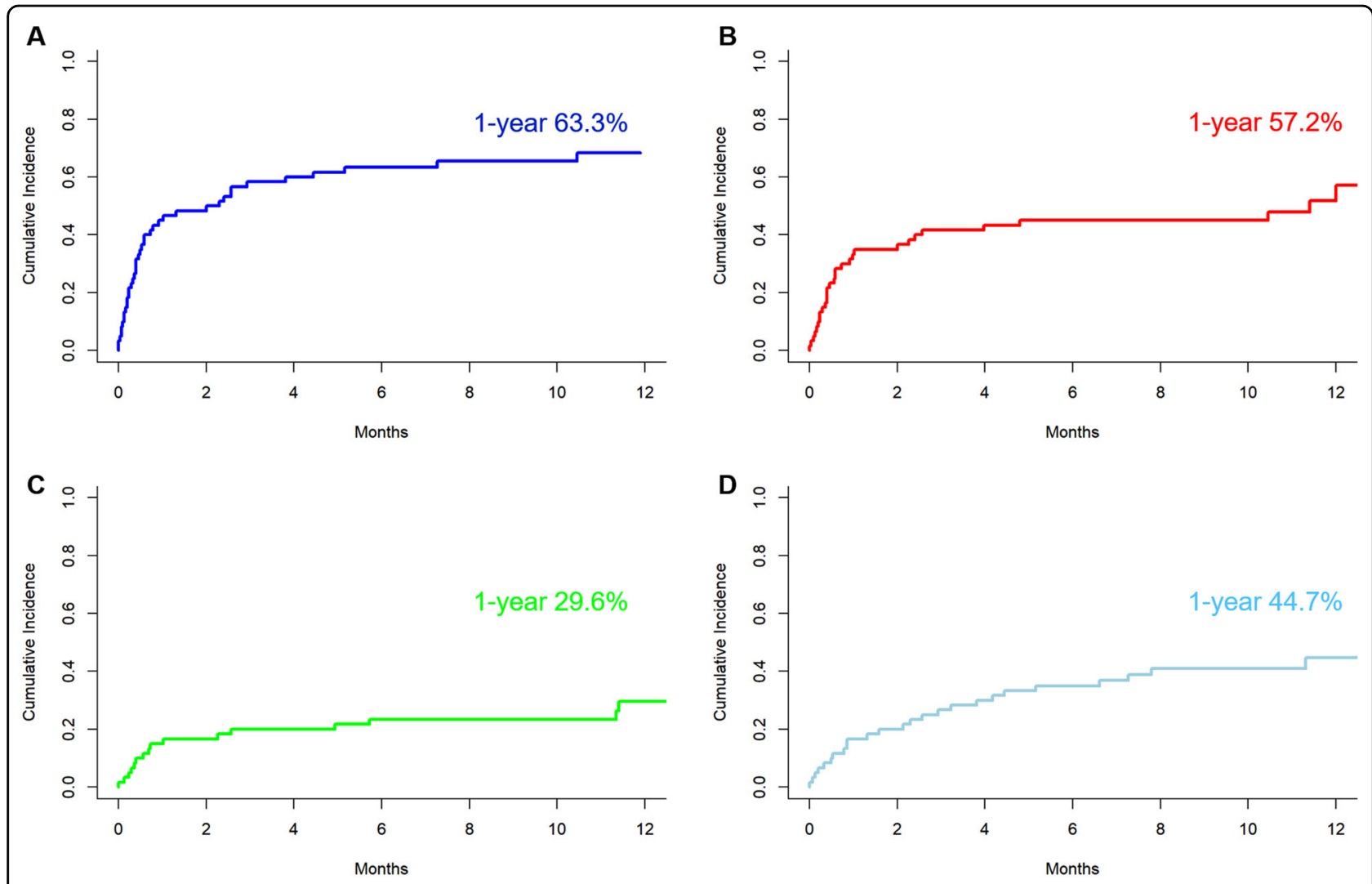

Fig. 4 Cumulative Incidence of infection. a Any infection. b Bacterial Infection. c Severe Bacterial Infection. d Viral Infection.

10 occurred after day 180 . Approximately $50 \%$ of viral infections were of mild severity $(n=17)$. Respiratory tract infections $(n=21)$ were the most common with rhinovirus being the most frequently recovered. There were 1 cytomegalovirus reactivation (viremia without organ dysfunction), 2 BK virus cystitis, and 2 herpes zoster reactivation (both of whom were on acyclovir prophylaxis). Pneumocystis jiroveci infection was identified in 1 patient at 9 months after CAR T cell infusion (4 months after pentamidine prophylaxis discontinuation).

\section{Risk factors associated with infection}

In the univariate analysis, impaired baseline performance status, ICANS grade $\geq 2$, and systemic corticosteroid exposure after CAR $\mathrm{T}$ cell infusion were associated with a higher incidence of overall infection (Table 5). In multivariate analysis, systemic corticosteroid was the only risk factor of infectious complications. Impaired performance status and previous infection 30 days before LD chemotherapy was independent predictors for severe bacterial infection (HR 3.98, 95\% CI 1.3-12.2). Patients with low IgG before LD chemotherapy had higher risk of viral infection after CAR T cells (HR 5.7, 95\% CI 2.3-14.3; Supplementary Table S7), however, IVIG replacement did not decrease the incidence of infection. CRS, tocilizumab administration, and procalcitonin were not associated with infection or severe bacterial infection. The incidence of infection was comparable between 47 patients who received CAR T cell therapy before March 2019 and 13 patients who were treated with CAR T cells after March 2019, when the standardized antimicrobial prophylaxis guideline was implemented (HR 1.22, 95\% CI 0.6-2.5).

\section{Impact of infection on patients' survival outcomes}

Of all infectious complications, one resulted in death attributed to influenza pneumonia despite a 10-day course of oseltamivir treatment. There was no association between infectious complications and mortality risk in CAR T cell-treated patients when analyzed by univariate cox regression.

\section{Discussion}

Our study reported comprehensive real-world data on infectious complications in DLBCL patients treated with commercially available CD19 CAR T cell products. Data from the pivotal studies of CD19 CAR T cell therapy in DLBCL demonstrated an incidence of $15-30 \%$ for severe infection ${ }^{13-15}$. The incidence of overall infection in our study was comparable to these landmark trials. Moreover, 
Table 4 Cumulative incidence of infection by causative pathogens at different follow up after chimeric antigen receptor T cell therapy.

\begin{tabular}{|c|c|c|c|c|}
\hline & 1 month $(95 \% \mathrm{Cl})$ & 3 months $(95 \% \mathrm{Cl})$ & 6 months $(95 \% \mathrm{Cl})$ & 1 year $(95 \% \mathrm{Cl})$ \\
\hline Overall Infection & $45.0(32.0-57.1)$ & $58.3(44.6-69.8)$ & $61.7(46.5-71.3)$ & $63.3(49.5-74.3)$ \\
\hline Bacterial Infection & $33.3(21.7-45.4)$ & $41.7(29.0-53.8)$ & $45.0(32.0-57.1)$ & $57.2(39.3-71.6)$ \\
\hline Severe Bacterial Infection & $15.0(7.30-25.2)$ & $20.0(11.0-31.0)$ & $23.3(13.5-34.7)$ & $29.6(17.4-42.9)$ \\
\hline Viral Infection & $16.7(8.50-27.2)$ & $26.7(16.2-38.3)$ & $35.0(23.1-47.1)$ & $44.7(30.2-58.3)$ \\
\hline Fungal Infection & $1.7(0.1-7.9)$ & $1.7(0.1-7.9)$ & $1.7(0.1-7.9)$ & $4.0(7.0-12.3)$ \\
\hline
\end{tabular}

$\mathrm{Cl}$ confidence interval.

the patterns of infection in our cohort were similar to the findings from previous reports ${ }^{5,7,10}$. Bacterial and viral infections were commonly observed, with bacteria being the most common pathogen, especially during the first 30 days $^{5,7,10}$. Recently, Cordeiro and colleagues reported the incidence of adverse events beyond day 90 from CAR $\mathrm{T}$ cell infusion ${ }^{16}$ and described a relatively low incidence of late infections (2.08 per patient-year), with most being of mild to moderate severity. Our study observed similar results with $71 \%$ of all infections considered mild to moderate. Upper respiratory tract infections were the most common infectious events. Serious infections occurred in $23.4 \%$ of DLBCL patients treated with commercial CD19 CAR T cell products; nonetheless, most infections were manageable and infection-related mortality was low similar to the results of previous reports ${ }^{5,7,17}$. In our study, one patient died from influenza A pneumonia at day +159 despite treatment with oseltamivir. Fungal infection was uncommon in patients treated with CAR T cells likely due to short duration of neutropenia ${ }^{5,18}$. One patient had Pneumocystis jirovecii pneumonia 4 months after pentamidine prophylaxis was stopped. Retrospectively, the patient's CD4 count was 44 cells $/ \mu \mathrm{L}$ at the time of infection, thus emphasizing the importance of implementing immune monitoring protocols to guide the duration of antimicrobial prophylaxis in these patients.

General practice for infection prophylaxis in patients treated with CAR $\mathrm{T}$ cell are heterogeneous and vary by institutions ${ }^{19}$. The recent European guidelines for antimicrobial prophylaxis and IVIG replacement in patients treated with CAR $\mathrm{T}$ cells ${ }^{20}$ was primarily based on the evidence from SCT patients ${ }^{21}$. Currently, the appropriate prophylactic approach in these patients remains unknown and requires further understanding of the immune reconstitution pattern and longer follow-up data. B cell aplasia is a well-known "off tumor and on target" phenomenon after CD19 CAR T cell therapy contributing to hypogammaglobulinemia in these patients. A quarter of patients in our cohort had $\operatorname{IgG}<400 \mathrm{mg} / \mathrm{dL}$, and $60 \%$ had $\mathrm{IgG}<600 \mathrm{mg} / \mathrm{dL}$. This finding was comparable to data from the JULIET trial ${ }^{14}$, which highlighted the baseline humoral immune defect in these patients. However, there are data showing persistent long-lived plasma cells after CAR $\mathrm{T}$ cell therapy ${ }^{22}$. In addition, Hill and colleagues recently demonstrated preserved anti-viral humoral immune response in patients treated with CD19 CAR $\mathrm{T}$ cells $\mathrm{s}^{23}$. The authors reported sustained anti-measle IgG level independent of the total IgG level in 95\% of patients. Moreover, overall anti-virome was preserved in most patients. Moreover, there was a low incidence of viral infection after day 90. In our study, there were 18 viral infectious episodes in 15 patients after day 100 with mild respiratory tract infection as the most common presentation similar to previous reports. Interestingly, we observed an increased risk of viral infection in patients with hypogammaglobulinemia, but no such correlation was seen with other types of infection (supplementary data). We hypothesize that IgG deficiency at baseline might indicate pre-existing depleted plasma cell and antibody repertoire, which may have a more critical impact on the ability to mount viral-specific neutralizing IgG and predispose patients to infection after CAR $\mathrm{T}$ cell therapy. The significance of hypogammaglobulinemia on the risk of infection in patients treated with CD19 CAR $\mathrm{T}$ cells warrants further study. In the ELIANA trial, all pediatric patients with precursor B acute lymphoblastic leukemia (ALL) received IVIG replacement. In contrast, the proportion of IVIG replacement among DLBCL patients treated in pivotal studies was lower and ranged around $20-60 \%{ }^{14,15,24}$. Only $30 \%$ of our patients received IVIG replacement, of which half had a history of preceding recurrent infection after CAR $\mathrm{T}$ cell therapy. The primary malignancy probably has a critical contribution to the risk of infection attributed to underlying immune function and kinetics of immune recovery. Data from patients with B-ALL indicated that $\mathrm{CD} 8^{+}$lymphocyte recovered early whereas $\mathrm{CD} 4^{+}$lymphocyte had delayed recovery after CAR $\mathrm{T}$ cell therapy ${ }^{25}$. Further studies on infection prophylaxis, immunization, and immune reconstitution in CAR $\mathrm{T}$ cell-treated patients are warranted. 
Table 5 Cox proportional hazard regression analysis for factors associated with all infection and severe bacterial infection after chimeric antigen receptor $T$ cell therapy.

\begin{tabular}{|c|c|c|c|c|}
\hline & \multicolumn{2}{|l|}{ Univariate analysis } & \multicolumn{2}{|l|}{ Multivariate analysis } \\
\hline & $\begin{array}{l}\text { Hazard ratio ( } 95 \% \text { confidence } \\
\text { interval) }\end{array}$ & $P$-value & $\begin{array}{l}\text { Hazard ratio ( } 95 \% \text { confidence } \\
\text { interval) }\end{array}$ & $P$-value \\
\hline \multicolumn{5}{|l|}{ All Infection } \\
\hline Age ( $\geq 60$ vs. $<60$ years) & $1.06(0.55-2.02)$ & 0.90 & N/A & N/A \\
\hline $\begin{array}{l}\text { CART product (Tisagenlecleucel vs. Axicabtagene } \\
\text { ciloleucel) }\end{array}$ & $0.70(0.33-1.48)$ & 0.40 & N/A & N/A \\
\hline Performance status ( $\geq 2$ vs. $0-1$ ) & $2.15(1.06-4.37)$ & 0.03 & $1.87(0.91-3.84)$ & 0.09 \\
\hline Transplant prior to CAR T cell therapy (Yes vs. No) & $0.57(0.26-1.24)$ & 0.20 & N/A & N/A \\
\hline Infection before CAR T cell therapy (Yes vs. No) & $0.84(0.44-1.59)$ & 0.60 & N/A & N/A \\
\hline $\begin{array}{l}\text { Baseline lactate dehydrogenase before } \\
\text { lymphodepletion (normal vs. high) }\end{array}$ & $1.13(0.60-2.10)$ & 0.70 & N/A & N/A \\
\hline Baseline immunoglobulin G (<400 vs. $\geq 400$ mg/dL) & $1.76(0.86-3.58)$ & 0.12 & N/A & N/A \\
\hline Cytokine release syndromes (grade $\geq 3$ vs. grade $0-2$ ) & $0.86(0.30-2.43)$ & 0.77 & N/A & N/A \\
\hline $\begin{array}{l}\text { Immune effector cell neurotoxicities (grade } \geq 2 \text { vs. } \\
\text { grade } 0-1 \text { ) }\end{array}$ & $2.27(1.10-4.71)$ & 0.03 & N/A & N/A \\
\hline Systemic corticosteroid during CAR T cell (Yes vs. No) & $2.18(1.08-4.41)$ & 0.03 & $2.22(1.05-4.67)$ & 0.03 \\
\hline Tocilizumab during CAR T cell (Yes vs. No) & $1.20(0.60-2.40)$ & 0.61 & N/A & N/A \\
\hline \multicolumn{5}{|l|}{ Severe bacterial infection } \\
\hline Age ( $\geq 60$ vs. $<60$ years) & $0.48(0.18-1.28)$ & 0.14 & N/A & N/A \\
\hline $\begin{array}{l}\text { CART product (Tisagenlecleucel vs. Axicabtagene } \\
\text { ciloleucel) }\end{array}$ & $0.62(0.18-2.18)$ & 0.50 & N/A & N/A \\
\hline Performance status ( $\geq 2$ vs. $0-1$ ) & $3.69(1.34-10.2)$ & 0.01 & $2.84(1.0-8.06)$ & 0.05 \\
\hline Transplant prior to CAR T cell therapy (Yes vs. No) & $0.89(0.29-2.75)$ & 0.80 & N/A & N/A \\
\hline Infection before CAR T cell therapy (Yes vs. No) & $4.69(1.60-13.7)$ & 0.005 & $3.98(1.30-12.20)$ & 0.01 \\
\hline $\begin{array}{l}\text { Baseline lactate dehydrogenase before } \\
\text { lymphodepletion (Normal vs. High) }\end{array}$ & $0.78(0.29-2.13)$ & 0.60 & N/A & N/A \\
\hline $\begin{array}{l}\text { Baseline Immunoglobulin G before lymphodepletion } \\
\text { (<400 vs. } \geq 400 \mathrm{mg} / \mathrm{dL} \text { ) }\end{array}$ & $1.86(0.67-5.12)$ & 0.20 & N/A & N/A \\
\hline Cytokine release syndromes (grade $\geq 3$ vs. grade $0-2$ ) & $2.18(0.62-7.73)$ & 0.22 & N/A & N/A \\
\hline $\begin{array}{l}\text { Immune effector cell neurotoxicities (grade } \geq 2 \text { vs. } \\
\text { grade } 0-1 \text { ) }\end{array}$ & $2.47(0.87-7.03)$ & 0.09 & N/A & N/A \\
\hline Systemic corticosteroid during CAR T cell (Yes vs. No) & $2.53(0.89-7.20)$ & 0.08 & N/A & N/A \\
\hline Tocilizumab during CAR T cell (Yes vs. No) & $1.86(0.66-5.26)$ & 0.24 & N/A & N/A \\
\hline
\end{tabular}

CAR chimeric antigen receptor, N/A not applicable.

In our study, we identified systemic corticosteroid as a predictor for infection after CAR $\mathrm{T}$ cell therapy whereas history of infection within 30 days before CAR $\mathrm{T}$ cell infusion was associated with severe bacterial infection, which may contribute to longer hospital stays in these patients. This observation is similar to another previous retrospective study ${ }^{8}$. We did not see an association between
CRS and infectious complications in our lymphoma cohort. Park and colleagues previously demonstrated severe CRS (grade $\geq 3$ ) as a risk factor for bacterial infection in adult BALL treated with CD19 CAR T cells ${ }^{7,10}$. Other risk factors for infection after CAR T cell therapy shown by previous studies included higher number of prior treatments, higher doses of CAR $\mathrm{T}$ cells, older age, previous history of 
infection, and CD22-specific CAR $\mathrm{T}$ cells ${ }^{5,8}$. Finally, a recent study described the association between double peak IL-6 pattern (second surge of serum IL-6 after initial normalization) and life-threatening infection ${ }^{26}$. Along with the current interest of anti-IL6 therapy in severe acute respiratory syndrome coronavirus 2 patients with respiratory failure ${ }^{27-34}$, it is at least worth noting that we did not observe an association between the use of tocilizumab and infections in this cohort.

Our study has unique strengths. We comprehensively analyzed the real-world data on patterns of infection, detailed information on relevant immune status and prophylactic strategies during the first year after CAR $\mathrm{T}$ cell therapy in patients with DLBCL from a dedicated lymphoma patient cohort. We acknowledge several limitations of this study. Besides its retrospective nature, immune function monitoring and infection prophylaxis were not prospectively studied in a systematic manner. Lastly, the relatively small number of patients included in the study could limit its statistical power.

In summary, infection is common in DLBCL patients treated with CD19 CAR T cells. However, most events occurred early after CAR T cell therapy and were largely manageable. The mechanism of infection in these patients is complex and multifactorial. Appropriate infection prophylaxis in these patients remain to be determined, and prospective clinical trials are warranted.

\footnotetext{
Acknowledgements

This research was supported in part by $\mathrm{NIH}$ award P01 CA23766 and $\mathrm{NIH/NCI}$ Cancer Center Support Grant P30 CA008748. The content is solely the responsibility of the authors and does not necessarily represent the official views of the National Institutes of Health. K.W. receives salary support from Parker Institute for Cancer Immunotherapy at Memorial Sloan Kettering Cancer Center. M.P. received salary support from an American Italian Cancer Foundation Post-Doctoral Research Fellowship and by AlL Milano e Provincia ONLUS.
}

\begin{abstract}
Author details
${ }^{1}$ Adult Bone Marrow Transplant Service, Department of Medicine, Memorial Sloan Kettering Cancer Center, New York, NY, USA. ${ }^{2}$ Division of Hematology and Research Unit in Translational Hematology, Department of Medicine, Chulalongkorn University, Bangkok, Thailand. 'ymphoma Service, Department of Medicine, Memorial Sloan Kettering Cancer Center, New York, NY, USA. ${ }^{4}$ Department of Medicine, Weill Cornell Medical College, New York, NY, USA. ${ }^{5}$ Division of Hematology, Oncology and Hemato-Oncology Department, Fondazione IRCCS Istituto Nazionale dei Tumori and University of Milan, Milan, Italy. ${ }^{6}$ Department of Biostatistics and Epidemiology, Memorial Sloan Kettering Cancer Center, New York, NY, USA. ${ }^{7}$ Department of Neurology, Memorial Sloan Kettering Cancer Center, New York, NY, USA. ${ }^{8}$ Critical Care Medicine Service, Department of Anesthesiology and Critical Care Medicine, Memorial Sloan Kettering Cancer Center, New York, NY, USA. ${ }^{9}$ Infectious Disease Service, Department of Medicine, Memorial Sloan Kettering Cancer Center, New York, NY, USA
\end{abstract}

\section{Author contributions}

K.W., M.L.P., S.K.S., and M.A.P. designed the study and wrote the paper. K.W., M.P., and M.G.R. collected the data and conducted the analysis. M.L.S., A.A., and M.A.M. participated in data collection. M.P. and M.G.R participated in the data analysis. J.R.F. and S.M.D. conducted the statistical analysis. C.L.B., G.L.S., M.S., P.B.D., C.S.S., B.D.S., and E.M. took care of the patients. All the authors reviewed and approved the paper.

\section{Conflict of interest}

K.W., M.P., J.R.F., S.M.D., A.A., M.L.S., M.A.M., and S.K.S. have no relevant conflict of interest. M.G.R. reports receiving honoraria from Takeda and Janssen Pharmaceutical. M.S. has served as a paid consultant for McKinsey \& Company, Angiocrine Bioscience, Inc., and Omeros Corporation. He has received research funding from Angiocrine Bioscience, Inc. He has served on an ad hoc advisory board for Kite-A Gilead Company. G.L.S. receives research funding from Amgen and Janssen Pharmaceutical. C.L.B. serves as a paid consultant for Life Sci, GLG, Juno/Celgene, Seattle Genetics and Kite/Gilead. She reports receiving research funding from Janssen Pharmaceutical, Novartis, Epizyme, Xynomics and Bayer. She receives honorarium from Dava Oncology. M.L.P. has served on ad hoc advisory board for Kite and Novartis. P.B.D. serves on the advisory board for Kite/Gilead. C.S.S. has served as a paid consultant on advisory boards for Juno Therapeutics, Sanofi-Genzyme, Spectrum Pharmaceuticals, Novartis, Genmab, Precision Biosciences, Kite, a Gilead Company, Celgene, Gamida Cell and GSK. He has received research funds for clinical trials from Juno Therapeutics, Celgene, Precision Biosciences and Sanofi-Genzyme. B.D.S. provides consultancy for Kite/Gilead, Juno/Celgene and Janssen. She also receives research support from ADC Therapeutics. M.A.P. reports honoraria from Kite/Gilead, Abbvie, Bellicum, Bristol-Myers Squibb, Incyte, Merck, Novartis, Nektar Therapeutics, Omeros, and Takeda. He serves on DSMBs for Servier and Medigene, and the scientific advisory boards of MolMed and NexImmune. He has received research support for clinical trials from Incyte, Kite/Gilead and Miltenyi Biotec. He serves in a volunteer capacity as a member of the Board of Directors of the American Society for Transplantation and Cellular Therapy (ASTCT) and Be the Match (National Marrow Donor Program, NMDP), as well as on the CIBMTR Cellular Immunotherapy Data Resource (CIDR) Committee.

\section{Publisher's note}

Springer Nature remains neutral with regard to jurisdictional claims in published maps and institutional affiliations.

Supplementary Information accompanies this paper at (https:/doi.org/ 10.1038/s41408-020-00346-7).

Received: 4 May 2020 Revised: 29 June 2020 Accepted: 21 July 2020 Published online: 05 August 2020

\section{References}

1. Yanez, L., Sanchez-Escamilla, M. \& Perales, M. A. CAR T cell toxicity: current management and future directions. Hemasphere. 3, e186 (2019).

2. Jain, T. et al. Use of chimeric antigen receptor $\mathrm{T}$ cell therapy in clinical practice for relapsed/refractory aggressive B cell non-Hodgkin lymphoma: an expert panel opinion from the american society for transplantation and cellular therapy. Biol Blood Marrow Transplant. 25, 2305-2321 (2019).

3. Nahas, G. et al. Persistent cytopenias after chimeric antigen receptor T-cell immunotherapy for CD19+ aggressive lymphoma: a single institution experience. Biol. Blood Marrow Transplant. 25, S180 (2019).

4. Fried, S. et al. Early and late hematologic toxicity following CD19 CAR-T cells. Bone Marrow Transplant. 54, 1643-1650 (2019).

5. Hill, J. A. et al. Infectious complications of CD19-targeted chimeric antigen receptor-modified T-cell immunotherapy. Blood. 131, 121-130 (2018).

6. Zhu, F., Hu, Y., Guoqing, W., Huang, H. \& Wu, W. Incidence and risk factors associated with infection after chimeric antigen receptor $\mathrm{T}$ cell therapy for relapsed/refractory B-cell malignancies. Blood. 134(Supplement_1), 3220 (2019).

7. Park, J. H. et al. Cytokine release syndrome grade as a predictive marker for infections in patients with relapsed or refractory B-cell acute lymphoblastic leukemia treated with chimeric antigen receptor T cells. Clin. Infect. Dis. 67, 533-540 (2018).

8. Mikkilineni, L. et al. Infectious complications associated with CAR T-cell therapy. Blood. 134(Supplement_1), 4449 (2019).

9. Syed, T. I. S. et al. Infections associated with CAR T therapy for treatment of hematological malignancies. Blood. 134(Supplement_1), 4442 (2019).

10. Vora, S. B. et al. Infectious complications following CD19 chimeric antigen receptor t-cell therapy for children, adolescents, and young adults. Open Forum Infect. Dis. 7, ofaa121 (2020). 
11. Young, J. H. et al. Infections after transplantation of bone marrow or peripheral blood stem cells from unrelated donors. Biol. Blood Marrow Transplant. 22 359-370 (2016).

12. Common Terminology Criteria for Adverse Events (CTCAE) Version 5.0: https:// ctep.cancer.gov/protocoldevelopment/electronic_applications/docs/ CTCAE_v5_Quick_Reference_8.5x11.pdf (2020).

13. Neelapu, S. S. et al. Axicabtagene Ciloleucel CAR T-Cell Therapy in Refractory Large B-Cell Lymphoma. N. Engl. J. Med. 377, 2531-2544 (2017).

14. Schuster, $\mathrm{S}$. J. et al. Tisagenlecleucel in adult relapsed or refractory diffuse large B-cell lymphoma. N. Engl. J. Med. 380, 45-56 (2019).

15. Abramson, J. S. et al. Pivotal safety and efficacy results from transcend NHL 001, a multicenter phase 1 study of Lisocabtagene Maraleucel (liso-cel) in relapsed/refractory (R/R) large B cell lymphomas. Blood. 134(Supplement_1), 241 (2019).

16. Cordeiro, A. et al. Late events after treatment with CD19-targeted chimeric antigen receptor modified T cells. Biol. Blood Marrow Transplant. 26, 26-33 (2020).

17. Riedell, P. A. et al. A multicenter retrospective analysis of clinical outcomes, toxicities, and patterns of use in institutions utilizing commercial axicabtagene ciloleucel and tisagenlecleucel for relapsed/refractory aggressive B-cell lymphomas. Blood. 134(Supplement_1), 1599 (2019).

18. Haidar, G. et al. Invasive mold infections after chimeric antigen receptormodified T-cell Therapy: a case series, review of the literature, and implications for prophylaxis. Clin. Infect. Dis. https://doi.org/10.1093/cid/ciz1127 (2019).

19. Mahmoudjafari, Z. et al. American Society for Blood and Marrow Transplantation Pharmacy Special Interest Group Survey on chimeric antigen receptor T cell therapy administrative, logistic, and toxicity management practices in the United States. Biol. Blood Marrow Transplant. 25, 26-33 (2019).

20. Yakoub-Agha, I. et al. Management of adults and children undergoing chimeric antigen receptor T-cell therapy: best practice recommendations of the European Society for Blood and Marrow Transplantation (EBMT) and the Joint Accreditation Committee of ISCT and EBMT (JACIE). Haematologica. 105, 297-316 (2020).
21. Bhella, S. et al. Choosing wisely BMT: American Society for Blood and Marrow Transplantation and Canadian Blood and Marrow Transplant Group's list of 5 tests and treatments to question in blood and marrow transplantation. Biol. Blood Marrow Transplant. 24, 909-913 (2018).

22. Bhoj, V. G. et al. Persistence of long-lived plasma cells and humoral immunity in individuals responding to CD19-directed CAR T-cell therapy. Blood. 128, 360-370 (2016).

23. Hill, J. A. et al. Durable preservation of antiviral antibodies after CD19-directed chimeric antigen receptor T-cell immunotherapy. Blood Adv. 3, 3590-3601 (2019).

24. Locke, F. L. et al. Long-term safety and activity of axicabtagene ciloleucel in refractory large B-cell lymphoma (ZUMA-1): a single-arm, multicentre, phase 12 trial. Lancet Oncol. 20, 31-42 (2019).

25. Wang, Y. et al. Kinetics of immune reconstitution after CD19 CAR-T cell therapy in ALL patients. Blood 134(Supplement_1), 1301 (2019).

26. Luo, $\mathrm{H}$. et al. Inflammatory signatures for quick diagnosis of life-threatening infection during the CAR T-cell therapy. J. Immunother. Cancer. 7, 271 (2019).

27. Xu, X. et al. Effective treatment of severe COVID-19 patients with Tocilizumab. Proc Natl. Acad. Sci. USA 117, 10970-10975 (2020).

28. Tocilizumab in COVID-19 pneumonia (TOCIVID-19). https://ClinicalTrials.gov/ show/NCT04317092 (2020).

29. A Study to evaluate the safety and efficacy of tocilizumab in patients with severe COVID-19 pneumonia. https:/ClinicalTrials.gov/show/NCT04320615 (2020).

30. Favipiravir combined with Tocilizumab in the treatment of corona virus disease 2019. https://ClinicalTrials.gov/show/NCT04310228 (2020).

31. Tocilizumab vs CRRT in management of cytokine release syndrome (CRS) in COVID-19. https://ClinicalTrials.gov/show/NCT04306705 (2020).

32. Tocilizumab for SARS-CoV2 severe pneumonitis. https://ClinicalTrials.gov/ show/NCT04315480 (2020).

33. Anti-il6 treatment of serious COVID-19 disease with threatening respiratory failure. https://ClinicalTrials.gov/show/NCT04322773 (2020).

34. Zhang, $X$. et al. First case of COVID-19 in a patient with multiple myeloma successfully treated with tocilizumab. Blood Adv. 4, 1307-1310 (2020). 